A REVIEW

\title{
Issues and challenges in Indian agriculture
}

\section{Shahid Jibran and Azra Mufti}

Received : 05.07.2019; Accepted : 27.09.2019

\begin{abstract}
Agriculture is considered to be the backbone of Indian Economy; it is considered to be one of the prime moving factors of economy and is responsible for generating huge dividends in the form of revenue. Inspite of high growth rate of Indian economy, it is still not in good shape, there are many issues and challenges that are paid lax attention. India is one of the chief suppliers of items like spices, pulses, saffron and milk, it contributes a major chunk to the GDP of nation, it impacts the lives of majority of Indians, however the figures are coming down. This paper tries to identify the major issues and challenges of Indian agriculture and what can be the possible solutions.
\end{abstract}

KEY WORDS : Indian agriculture, Challenges, Issues, Solutions

How to cite this paper : Jibran, Shahid and Mufti, Azra (2019). Issues and challenges in Indian agriculture. Internat. J. Com. \& Bus. Manage, 12(2) : 85-88, DOI: 10.15740/HAS/IJCBM/12.2/85-88. Copyright@ 2019: Hind Agri-Horticultural Society.

E-mail: shd.jibran@gmail.com 